\title{
Issues in Measuring Generic Skills Using Self-Administered Questionnaire in a Community College in Hong Kong
}

\author{
Wai Tung Ho, Joseph Chi Ho So \\ The Hong Kong Polytechnic University, Hong Kong Community College, Hong Kong \\ Email: ccwtho@hkcc-polyu.edu.hk,ccso@hkcc-polyu.edu.hk
}

Received 5 June 2016; accepted 24 July 2016; published 27 July 2016

Copyright (C) 2016 by authors and OALib.

This work is licensed under the Creative Commons Attribution International License (CC BY). http://creativecommons.org/licenses/by/4.0/

(c) (i) Open Access

\section{Abstract}

In this study, we evaluate the reliability and validity of Self-Assessment of All-Round Development (SAARD) Questionnaire developed by The Hong Kong Polytechnic University when applied to two cohorts of students in Hong Kong Community College. Despite of the drastic changes in the educational system in Hong Kong, the SAARD questionnaire can still maintain a similar level of reliability as compared to the pilot study carried out a decade ago. However, this study reveals that there are too many items in the questionnaire and fatigue effect is affecting the reliability of items near the end of the survey. In addition, three of the items in the questionnaire have extremely large variations, implying potential problems in the wording of questions corresponding to these items. Remedies are also proposed in this study to alleviate the problems identified in the SAARD questionnaire.

\section{Keywords}

Generic Skills, Fatigue Effect, Reliability, Questionnaire

Subject Areas: Education

\section{Introduction}

With the explosion of association degree programs in Hong Kong in the last decade, educators and administrators of the sector are eager to assess the effectiveness of associate degree education in Hong Kong. The success of these programs is not only being evaluated based on the academic achievements of the students but also the generic skills they developed in their college years. These generic skills are often essential to a student's future development beyond the classroom. Many researches were devoted to the understanding of generic skills and factors in driving the development of generic skills [1]-[7]. 
In this article, we will look at the generic skill assessment approaches employed by Hong Kong Community College (HKCC), a subsidiary of The Hong Kong Polytechnic University (PolyU). The college is one of the largest associate degree institute in Hong Kong. In HKCC, generic skills are integral part of learning objectives of each program. Direct and indirect measures are employed to assess graduates' academic competency as well as their generic skills. Direct measures used include measures embedded in assignments, tests, projects and presentations. While indirect measures are usually used to collect assessments from the perspective of the college's articulation partners, such as universities and employers.

One direct measure used in assessing students' generic skills is the Self-Assessment of All-Round Development (SAARD) questionnaire developed by PolyU in 2006 (Fung et al. [8] [9]). In HKCC, samples of freshmen and graduates are asked to complete the SAARD questionnaire. The results enable the college to evaluate the effectiveness of their programs and student development activities in promoting generic skills. Due to its critical role, it is important to ensure the reliability of SAARD questionnaire. The reliability and validity of the SAARD questionnaire were evaluated in depth by Fung et al. [8] [9] in their pilot study conducted in 2006. The questionnaire was found to be effective in measuring various generic skills of university students. However, the education sector in Hong Kong has gone through a number of significant changes in the last decade. That includes the rapid expansion of the associate degree sector, adoption of 4-year curriculum in the university and the transition to Hong Kong Diploma of Education (DSE) in secondary schools. Since all these changes lead to a change in the student population as well as their skill sets when entering college. It becomes an urgent matter to assess the reliability of SAARD which is developed almost a decade ago and its applicability in assessing generic skills of today's students.

\section{About the SAARD Questionnaire}

The SAARD questionnaire has 56 questions covering 14 generic skills: communications; creative thinking; critical thinking; cultural appreciation; entrepreneurship; EQ \& psychological wellness; global outlook; healthy lifestyle; interpersonal effectiveness; leadership; lifelong learning; problem solving; social and national responsibility; and teamwork. Each generic skill is covered by 4 questions using a 7-point Likert scale (1 point $=$ not well, 7 point $=$ very well).

In HKCC, the survey is carried out on each cohort of students in two phases. In the first phase, a sample of students will be selected to complete the questionnaire at "entry", that is their first semester of study in the college. In the second phase, another sample of students will be selected at "exit", that is their last semester of study in the college. The change in generic skills over the two-year period of their studies in the college is of interest to various parties in the college. To improve the response rate, the survey is typically carried out during class hours. The collected data will be merged with administrative data for further statistical analysis. Analyses of the data collected can be found in (So et al. [10]).

\section{Potential Issues of SAARD}

As described above, SAARD was originally developed in 2006 for use in PolyU covering students in higher diploma to postgraduate programs. The students in HKCC are similar in level to the higher diploma students in PolyU. Despite of the similarity, it is reasonable to question if the SAARD is still a good instrument for measuring generic skills consider the drastic changes in the education system in secondary and tertiary levels. In particular, we will look at the student cohorts admitted to HKCC in 2011/12 academic year and 2013/14 academic year. These two cohorts represent the student populations who are under A-Level curriculum and DSE curriculum respectively. Using the data collected from the two cohorts mentioned above, we will study the reliability and validity of the SAARD survey by comparing to the PolyU pilot study in 2006 .

The second issue of SAARD is the length of the questionnaire. In order to cover 14 different generic skills, 4 questions are asked for each of the generic skill, giving us a total of 56 questions. It is a concern that the quality of data collected near the end of the questionnaire is affected by fatigue effect. From the administration point of view, a long questionnaire is also undesirable because SAARD surveys are normally done during class hours. A lengthy questionnaire will undoubtedly cause unnecessary interruption to teaching.

\section{About the Samples and the Cohorts}

The data being used in this study were collected from two cohorts of students entering the college in 2010 and 
2011 academic years. The choice of these cohorts instead of newer cohorts enables us to validate published results published by PolyU in 2006. Due to the secondary school reforms, later student cohorts might behave differently when completing the SAARD survey. The analysis of generic skills of later student cohorts will be done in a separate study (Table 1 ).

For each of the two cohorts in this study, random samples of students were asked to complete the SAARD questionnaire at the beginning of their first semester in the college (i.e. entry survey). At the end of the last semester of their studies, another random sample of students was asked to complete the SAARD questionnaire.

\section{Reliability Analysis of SAARD Surveys}

To assess the quality of the measurements obtained in our survey, reliability statistics of our studies are compared to the results of the PolyU pilot conducted in 2006. Table 2 and Table 3 show the Cronbach alphas and mean inter-item correlations for the entire questionnaire and the 14 scales being measured.

The reliability statistics of the two HKCC cohorts are mostly in line with the PolyU pilot. The smaller sample sizes at "Exit" have only caused a mild degradation in the reliability statistics. Among all scales, Social and National Responsibility has the lowest Cronbach alpha and mean inter-item correlations across the four samples. This indicates potential issues of the four items used in this scale. The exact wordings of the four items under Social and National Responsibility are:

Table 1. Sample sizes of 2010 and 2011 cohorts.

\begin{tabular}{ccc}
\hline Sample Size & 2010/11 Cohort & 2011/12 Cohort \\
\hline Entry (beginning of the first semester) & 1377 & 933 \\
Exit (end of the last semester) & 564 & 347 \\
\hline
\end{tabular}

Table 2. Reliability of SAARD questionnaire 2010/11 cohort.

\begin{tabular}{|c|c|c|c|c|c|c|c|}
\hline \multirow[b]{2}{*}{ Scale } & \multirow{2}{*}{$\begin{array}{l}\text { No. of } \\
\text { Items }\end{array}$} & \multicolumn{2}{|c|}{ HKCC 2010/11 (Entry) } & \multicolumn{2}{|c|}{ HKCC 2010/11 (Exit) } & \multicolumn{2}{|c|}{$\begin{array}{l}\text { Result from PolyU Pilot } \\
\text { (Early 2006) }\end{array}$} \\
\hline & & $\begin{array}{l}\text { Cronbach } \\
\text { alpha }\end{array}$ & $\begin{array}{c}\text { Mean } \\
\text { Inter-item } \\
\text { correlation }\end{array}$ & $\begin{array}{l}\text { Cronbach } \\
\text { alpha }\end{array}$ & $\begin{array}{c}\text { Mean } \\
\text { Inter-item } \\
\text { correlation }\end{array}$ & $\begin{array}{l}\text { Cronbach } \\
\text { alpha }\end{array}$ & $\begin{array}{c}\text { Mean } \\
\text { Inter-item } \\
\text { correlation }\end{array}$ \\
\hline Overall & 56 & 0.9667 & 0.3417 & 0.9596 & 0.2978 & 0.95 & 0.25 \\
\hline Creative Thinking & 4 & 0.8025 & 0.5040 & 0.7520 & 0.4312 & & \\
\hline Problem Solving & 4 & 0.8207 & 0.5337 & 0.7736 & 0.4607 & & \\
\hline Critical Thinking & 4 & 0.7775 & 0.4662 & 0.7136 & 0.3838 & & \\
\hline Life Long Learning & 4 & 0.7738 & 0.4609 & 0.7345 & 0.4088 & & \\
\hline Leadership & 4 & 0.8305 & 0.5506 & 0.7942 & 0.4911 & & \\
\hline Teamwork & 4 & 0.7345 & 0.4089 & 0.7072 & 0.3765 & & \\
\hline Communication & 4 & 0.7819 & 0.4726 & 0.7792 & 0.4687 & Min: 0.61 & Min: 0.30 \\
\hline EQ \& Psy. Wellness & 4 & 0.8012 & 0.5019 & 0.7700 & 0.4556 & Max: 0.91 & Max: 0.70 \\
\hline Interpersonal Effectiveness & 4 & 0.8096 & 0.5153 & 0.7664 & 0.4506 & & \\
\hline Cultural Appreciation & 4 & 0.8715 & 0.6291 & 0.8794 & 0.6458 & & \\
\hline Global Outlook & 4 & 0.8216 & 0.5351 & 0.7994 & 0.4991 & & \\
\hline Social \& National Responsibility & 4 & 0.6908 & 0.3584 & 0.5738 & 0.2518 & & \\
\hline Entrepreneurship & 4 & 0.8506 & 0.5874 & 0.8366 & 0.5614 & & \\
\hline Health Responsibility & 4 & 0.7355 & 0.4101 & 0.7069 & 0.3762 & & \\
\hline
\end{tabular}


Table 3. Reliability of SAARD questionnaire 2011/12 cohort.

\begin{tabular}{|c|c|c|c|c|c|c|c|}
\hline \multirow[b]{2}{*}{ Scale } & \multirow{2}{*}{$\begin{array}{l}\text { No. of } \\
\text { Items }\end{array}$} & \multicolumn{2}{|c|}{ HKCC 2011/12 (Entry) } & \multicolumn{2}{|c|}{ HKCC 2011/12 (Exit) } & \multicolumn{2}{|c|}{$\begin{array}{l}\text { Result from PolyU Pilot } \\
\text { (Early 2006) }\end{array}$} \\
\hline & & $\begin{array}{c}\text { Cronbach } \\
\text { alpha }\end{array}$ & $\begin{array}{c}\text { Mean } \\
\text { Inter-item } \\
\text { correlation }\end{array}$ & $\begin{array}{l}\text { Cronbach } \\
\text { alpha }\end{array}$ & $\begin{array}{c}\text { Mean } \\
\text { Inter-item } \\
\text { correlation }\end{array}$ & $\begin{array}{l}\text { Cronbach } \\
\text { alpha }\end{array}$ & $\begin{array}{c}\text { Mean } \\
\text { Inter-item } \\
\text { correlation }\end{array}$ \\
\hline Overall & 56 & 0.9636 & 0.3210 & 0.9636 & 0.3210 & 0.95 & 0.25 \\
\hline Creative Thinking & 4 & 0.7564 & 0.4370 & 0.7564 & 0.4370 & & \\
\hline Problem Solving & 4 & 0.7870 & 0.4801 & 0.7870 & 0.4801 & & \\
\hline Critical Thinking & 4 & 0.7117 & 0.3816 & 0.7117 & 0.3816 & & \\
\hline Life Long Learning & 4 & 0.7544 & 0.4344 & 0.7544 & 0.4344 & & \\
\hline Leadership & 4 & 0.8300 & 0.5496 & 0.8300 & 0.5496 & & \\
\hline Teamwork & 4 & 0.7489 & 0.4272 & 0.7489 & 0.4272 & & \\
\hline Communication & 4 & 0.7698 & 0.4553 & 0.7698 & 0.4553 & Min: 0.61 & Min: 0.30 \\
\hline EQ \& Psy. Wellness & 4 & 0.7958 & 0.4934 & 0.7958 & 0.4934 & Max: 0.91 & Max: 0.70 \\
\hline Interpersonal Effectiveness & 4 & 0.8011 & 0.5017 & 0.8011 & 0.5017 & & \\
\hline Cultural Appreciation & 4 & 0.8761 & 0.6387 & 0.8761 & 0.6387 & & \\
\hline Global Outlook & 4 & 0.8132 & 0.5212 & 0.8132 & 0.5212 & & \\
\hline Social \& National Responsibility & 4 & 0.5865 & 0.2618 & 0.5865 & 0.2618 & & \\
\hline Entrepreneurship & 4 & 0.8199 & 0.5323 & 0.8199 & 0.5323 & & \\
\hline Health Responsibility & 4 & 0.7337 & 0.4078 & 0.7337 & 0.4078 & & \\
\hline
\end{tabular}

1) I weigh carefully ethical/moral issues before taking actions.

2) I avoid talking on my mobile phone inside libraries or cinemas.

3) I help those in need by taking part in voluntary social services, money donations, or other activities.

4) I care about what I can do for the good of my country.

In order to have a better understanding of the problem, we calculated at the correlations of the four items of 2011/12 cohort at "Entry" in Table 4.

From Table 4, we can see that the 2nd item has the least correlation with other items in the scale, indicating that the 2 nd item is not suitable for this scale. One possibility for such problem is the extensive scope of the scale Social and National Responsibility. The 2nd item is microscopic in nature as compared to the other items in the scale, which may explain the disparity observed. It is recommended to either drop the 2 nd item or revise the item to better align with other items in the same scale.

\section{Anomalies in SAARD Survey}

To check if there is any anomaly with the responses collected from the SAARD survey, the variances of the 56 questions are plotted sequentially in Figure 1 for the two cohorts of students at entry and exit (a total of 4 samples). The plot reveals several interesting patterns. First of all, the variations of the responses are strikingly similar for the four samples under study. Consistency across different samples is desirable as we want a survey instrument that produces predictable results over time. However, the plot also reveals some undesirable patterns. We can observe that the variances of the 56 questions are increasing as we progress to the end of the questionnaire. Furthermore, there are several questions have exceptionally large variances, namely question 46,48 and 55 .

The increasing trend in variances can be confirmed by regressing the question variance on question id. As the question variances are computed on the same set of data, a first order auto regressive correlation structure AR(1) is used to adjust for potential correlations across questions. The slope of the model can be interpreted as the rate 
of increase in variations of the questions as the respondent proceed through the questionnaire. Such model is fitted to the two cohorts at both Entry and Exit. The slopes of these models are reported in Table 5. The slopes in the four models are all highly significant even after the exclusion of questions with extreme variations near the end of the questionnaire. Although the slopes seem small, the change in variance can be significant if the questionnaire is long enough. In our case, the questionnaire has 56 questions, which implies the variance of the last question can be greater that of question one by as much as 0.56 for a slope of 0.01 .

The two undesirable features hinted at two potential problems in the survey. The first one is the fatigue effect of working on a lengthy survey. Fatigue is a well-known issue in survey design and it was studied by many survey researchers such as Herzog and Bachman [11]. The second anomaly is the sharp increase in variances of question 46, 48 and 55. To get a perspective of the magnitude of the variations observed, we can compare them to the situation where respondents answering a 7-point Likekert scale question randomly. If responses are distributed randomly over the 7 choices, a simple calculation will yield a theoretical variance of 4 . For example, the variance of question 46 is beyond 3 , which is getting close to the situation of random responses. The three items with abnormal variations are:

Table 4. Correlations of social and national responsibilities items.

\begin{tabular}{ccccc}
\hline Pearson Correlations & Item 1 & Item 2 & Item 3 & Item 4 \\
\hline Item 1 & 1.000 & & & \\
Item 2 & $\mathbf{0 . 2 3 8 5}$ & 1.0000 & & \\
Item 3 & 0.2873 & $\mathbf{0 . 1 4 1 7}$ & 1.0000 & \\
Item 4 & 0.4111 & $\mathbf{0 . 2 1 2 0}$ & 0.3606 & 1.0000 \\
\hline
\end{tabular}

\begin{tabular}{cccc} 
Table 5. Rate of increase in question variances. & \\
\hline Cohort & Entry/Exit & Slope (p-value) & $\begin{array}{c}\text { Slope (p-value) } \\
\text { Excluding question 46, 48, 55 }\end{array}$ \\
\hline \multirow{2}{*}{2010} & Entry & $0.010(<0.001)$ & $0.007(0.002)$ \\
& Exit & $0.013(<0.001)$ & $0.009(<0.001)$ \\
2011 & Entry & $0.012(<0.001)$ & $0.007(0.044)$ \\
& Exit & $0.013(<0.001)$ & $0.009(0.003)$ \\
\hline
\end{tabular}

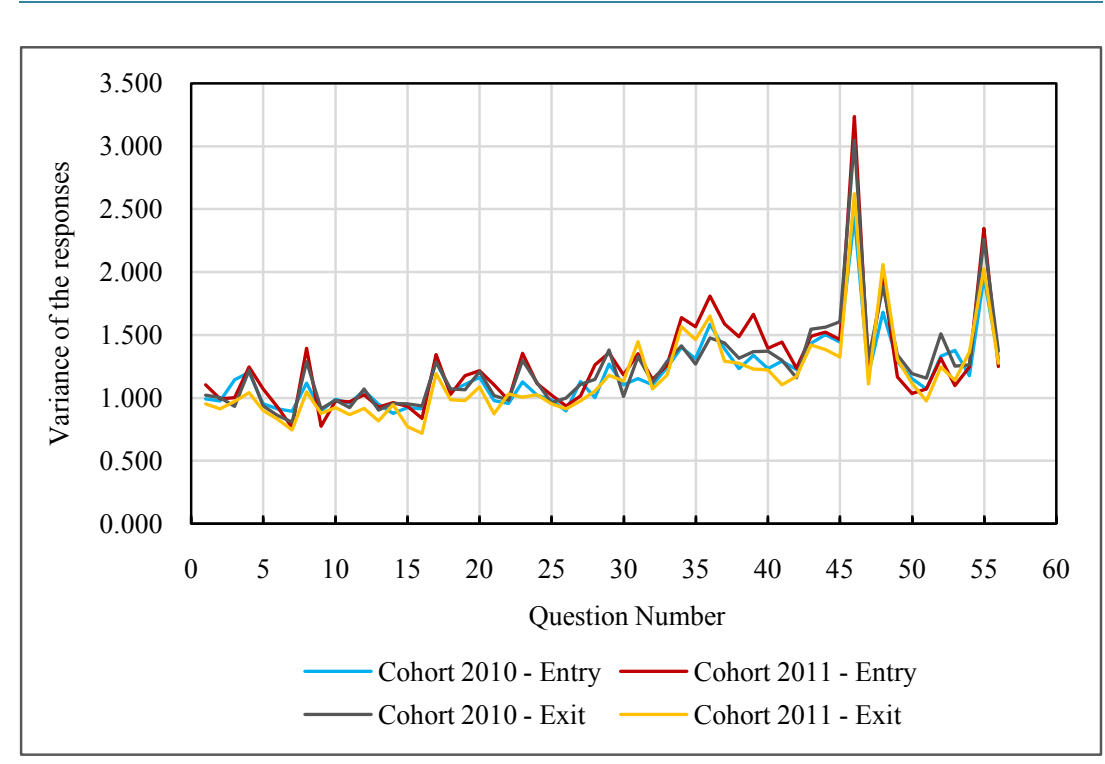

Figure 1. Variances of all questions in different samples. 
Item 46: I exercise for 20 - 30 minutes at least twice a week.

Item 48: I engage in short walks or other mild physical activities every week.

Item 55: I avoid talking on my mobile phone inside libraries or cinema.

The large variations to these three items may due to imprecise wording of the questions. For item 46 and 48 , both of them involve time duration and quantity of activities under consideration. These can be considered as a double barrel question, which are difficult for respondents to answer. Item 55 may also suffer from a similar problem as the question is asking for the respondent's activities in two different situations, namely libraries and cinema. There is a possibility that the respondents' behaviors in libraries and cinema are very different due to the nature of these environments. A rewording of these questions will therefore be needed. Alternatively, we can consider dropping these 3 questions from SAARD.

\section{Construct Validity of SAARD}

In this section, we evaluate if the SAARD surveys conducted in HKCC are measuring the same set of constructs. The evaluation is done by comparing the latent factors recovered from HKCC SAARD surveys to that of identified in PolyU pilot study.

In the PolyU pilot conducted in 2006, they identified an 11-factor solution for the SAARD survey. The factors identified together with their corresponding items are listed in Table 6.

To facilitate the comparison with PolyU pilot study, exploratory factor analysis will first be applied to the HKCC SAARD survey data. The results are summarized in Table 7. For the two HKCC cohorts, percentages of variances explained by the top 11 factors range from $58.46 \%$ to $62.21 \%$. On the contrary, the PolyU pilot can only explain a much lower percentage of the variances, $48.54 \%$. This suggests that that an 11 -factor model could be sufficient for data collected by HKCC SAARD survey. Alternatively, we also look for important factors with eigenvalues greater than 1 . Number of factors identified based on eigenvalue method ranges from 8 to 11 . In particular, number of factors identified for 2011 cohort is exactly the same as the PolyU pilot.

\begin{tabular}{|c|c|}
\hline Factors & Items in SAARD \\
\hline F1 Communication & $20,21,23,28$ \\
\hline F2 Cultural Appreciation & $37,39,43,44$ \\
\hline F3 EQ and Psychological Wellness & $32,33,34,36$ \\
\hline F4 Entrepreneurship & $47,49,50,51$ \\
\hline F5 Global Outlook & $38,40,41,42$ \\
\hline F6 Interpersonal Effectiveness & $29,30,31,35$ \\
\hline F7 Social and National Responsibility & $45,52,53,55$ \\
\hline $\begin{array}{l}\text { F8 Cognitive and Learning Competence } \\
\text { - Critical Thinking } \\
\text { - Creative Thinking } \\
\text { - Problem Solving } \\
\text { - } \quad \text { Life-long Learning }\end{array}$ & $\begin{array}{c}1,2,6,9 \\
4,5,10,12 \\
7,13,14,16 \\
3,8,11,15\end{array}$ \\
\hline $\begin{array}{c}\text { F9 Working in Groups } \\
\text { - Leadership } \\
\text { - Teamwork }\end{array}$ & $\begin{array}{l}18,19,24,26 \\
20,21,23,28\end{array}$ \\
\hline $\begin{array}{l}\text { F10 Healthy Lifestyle } \\
\text { - Engagement in Physical Activity }\end{array}$ & 46,48 \\
\hline $\begin{array}{l}\text { F11 Healthy Lifestyle } \\
\text { - Health Responsibility }\end{array}$ & 54,56 \\
\hline
\end{tabular}


Table 7. Exploratory factor analysis results.

\begin{tabular}{cccc}
\hline Cohort & Entry/Exit & $\begin{array}{c}\text { \% of variances explained } \\
\text { with 11 factors }\end{array}$ & $\begin{array}{c}\text { No. of factors with } \\
\text { eigenvalues > }\end{array}$ \\
\hline \multirow{2}{*}{2006} & N/A & $48.54 \%$ & Not available \\
& Entry & $58.46 \%$ & 8 \\
2010 & Exit & $57.74 \%$ & 10 \\
& Entry & $58.48 \%$ & 11 \\
\hline
\end{tabular}

Table 8. Confirmatory factor analysis results.

\begin{tabular}{cccc}
\hline Cohort & Entry/Exit & CFI & RMSEA \\
\hline 2006 & N/A & 0.90 & 0.040 \\
& Entry & 0.93 & 0.040 \\
2010 & Exit & 0.90 & 0.043 \\
& Entry & 0.87 & 0.046 \\
& Exit & 0.87 & 0.050 \\
\hline
\end{tabular}

To further validate if a 11-factor model is appropriate, a confirmatory factory analysis is used to assess the goodness of fit of the 11-factor model by using comparative fit index (CFI) and root mean square error of approximation (RMSEA). RMSEA in Table 8 are all less than or equal to 0.05 , which can be considered as good fits according to MacCallumetal [12]. Comparing to the RMSEA of PolyU pilot, the 11-factor model achieved similar fit to the SAARD data collected in HKCC. In terms of CFI, the fits are also comparable to that of PolyU pilot.

\section{Conclusions and Recommendations}

In this study, we evaluated the reliability and construct validity of the SAARD when applied to the population of associate degree students in HKCC. The results indicated that an 11-factor model can be generalized to the associate degree population in HKCC. However, we also uncovered several deficiencies in the SAARD instrument.

The first issue identified is the potential fatigue effect as respondents proceed through the questionnaire. The effect has a direct impact on the reliability of items near the end of the questionnaire. With the inflated variances of the affected items, the power of hypothesis tests carried out on items near the end of the survey will be lowered. The problem can be alleviated by reducing the length of the survey. A common recommendation in structural equation modeling is to have a minimum of 3 items per construct [13]. Since the SAARD questionnaire is using four items per construct, there is still room for reducing the number of items per construct to three. However, such reduction should not be done by subjective evaluation of the questions alone. One can take into account of the results obtained from the confirmatory factor analysis model. A possibility is to take out the items with the smallest factor loading, in order words, the items with least contribution to their corresponding constructs. In addition to the removal of items least associated with their intended constructs, the questions corresponding to the three erratic items should be revised to alleviate the ambiguities in those questions.

\section{References}

[1] Braskamp, L.A., Trautvetter, L.C. and Ward, K. (2006) Putting Students First: How Colleges Develop Students Purposefully. Anker Publishing Company, Bolton.

[2] Braxton, J.M. (2009) Understanding the Development of the Whole Person. Journal of College Student Development, 50, 573-575. http://dx.doi.org/10.1353/csd.0.0100 
[3] Evans, N.J., Forney, D.S., Guido, F.M., Patton, L.D. and Renn, K.A. (2010) Student Development in College. 2nd Edition, Jossey-Bass, San Francisco.

[4] Kuh, G.D. (2009) What Student Affairs Professionals Need to Know about Student Engagement. Journal of College Student Development, 50, 683-706. http://dx.doi.org/10.1353/csd.0.0099

[5] Baxter Magolda, M.B. (2009) The Activity of Meaning Making: A Holistic Perspective on College Student Development. Journal of College Student Development, 50, 621-639. http://dx.doi.org/10.1353/csd.0.0106

[6] Pizzolato, J.E., Brown, E.L., Hicklen, S.T. and Chaudhari, P. (2009) Student Development, Student Learning: Examining the Relation between Epistemologic Development and Learning. Journal of College Student Development, 50, 475-490. http://dx.doi.org/10.1353/csd.0.0093

[7] Taylor, K.B. (2008) Mapping the Intricacies of Young Adults' Developmental Journey from Socially Prescribed to Internally Defined Identities, Relationships, and Beliefs. Journal of College Student Development, 49, 215-234. http://dx.doi.org/10.1353/csd.0.0005

[8] Fung, D., Lee, W. and Wong, S.L.P. (2006) Project on Assessing the Development of Generic Competencies of PolyU Students-Report of Findings. Student Affairs Office and Educational Development Centre, Hong Kong Polytechnic University, Hong Kong.

[9] Fung, D., Lee, W. and Wong, S.L.P. (2007) A New Measure of Generic Competencies. Key Competencies-Skills for Life 2007 Conference, London, 12-13 July 2007.

[10] So, C.H.J., Lai, S.F.H., Lam, D. and So, Y.L. (2011) Mapping the Impact on Holistic Development: A Study of the Relationship between Generic Skills and Academic Discipline Among Hong Kong Associate Degree Students. ICERI 2011 Proceedings, Madrid, 14-16 November, 2011, 6630-6638.

[11] Herzog, A.R. and Bachman, J.G. (1981) Effects of Questionnaire Length on Response Quality. Public Opinion Quarterly, 45, 549-559. http://dx.doi.org/10.1086/268687

[12] MacCallum, R.C., Browne, M.W. and Sugawara, H.M. (1996) Power Analysis and Determination of Sample Size for Covariance Structure Modeling. Psychological Methods, 1, 130-149. http://dx.doi.org/10.1037/1082-989X.1.2.130

[13] Hair, J.F., Black, W.C., Babin, B.J. and Anderson, R.E. (2010) Multivariate Data Analysis. 7th Edition, Pearson, New York.

\section{Submit or recommend next manuscript to OALib Journal and we will provide best service for you:}

- Publication frequency: Monthly

- 9 subject areas of science, technology and medicine

- Fair and rigorous peer-review system

- Fast publication process

- Article promotion in various social networking sites (LinkedIn, Facebook, Twitter, etc.)

- Maximum dissemination of your research work

Submit Your Paper Online: Click Here to Submit

Contact Us: service@oalib.com 